\title{
VALIDATION OF THE NEW PROCEDURES FOR EVALUATING PARAMETERS OF CRUSTAL EARTHQUAKES CAUSED BY LONG FAULTS FOR GROUND MOTION PREDICTION
}

\author{
Dianshu Ju ${ }^{1}$, Kazuo Dan ${ }^{2}$, Hiroyuki Fujiwara ${ }^{3}$, and Nobuyuki Morikawa ${ }^{4}$ \\ ${ }^{1}$ Senior Researcher, Ohsaki Research Institute, Inc., Japan \\ ${ }^{2}$ Research Fellow, Ohsaki Research Institute, Inc., Japan \\ ${ }^{3}$ Director, National Research Institute for Earth Science and Disaster Resilience, Japan \\ ${ }^{4}$ Senior Researcher, National Research Institute for Earth Science and Disaster Resilience, Japan
}

\begin{abstract}
Two new procedures for evaluating fault parameters of asperity models for predicting strong ground motions from crustal earthquakes had been proposed: one is for long strike-slip faults by Dan et al. (2011) and the other is for long reverse faults by Dan et al. (2015). The procedures are based on important statistical findings that the average dynamic stress drop is constant, $3.4 \mathrm{MPa}$ on strike-slip faults with the seismic moment larger than $7.5 \times 10^{18} \mathrm{~N}-\mathrm{m}$ and $2.4 \mathrm{MPa}$ on reverse faults with the seismic moment larger than $2 \times 10^{19} \mathrm{~N}-\mathrm{m}$, and that the dynamic stress drop on the asperities is also constant, $12.2 \mathrm{MPa}$ on the strike-slip faults and $18.7 \mathrm{MPa}$ on the reverse faults. In order to validate the new procedure for long strike-slip faults, we made an asperity model for a strike-slip fault $141 \mathrm{~km}$ long by this procedure, predicted ground motions, and showed that the predicted velocity motions, velocity response spectra, PGA's, and PGV's agreed well with the observed ones in the 1999 Kocaeli, Turkey, earthquake $\left(M_{W} 7.6\right)$. We also made an asperity model for a reverse fault $279 \mathrm{~km}$ long by the new procedure for long reverse faults, and showed that the predicted velocity motions, PGA's, and PGV's agreed well with the observed ones in the 2008 Wenchuan, China, earthquake $\left(M_{W} 7.9\right)$.
\end{abstract}

\section{INTRODUCTION}

In the 1995 Kobe, Japan, earthquake $\left(M_{W} 6.8\right)$, severe-damage belt zone was formed by directivity pulses. Matsushima and Kawase (2006) showed that these directivity pulses had been generated on the asperities at the source. Based on their research, the asperity model has been adopted as a fault model for predicting strong ground motions in Japan (e.g., Headquarters of Earthquake Research Promotion, 2005a). The asperity model consists of asperities that have high stress drops and generate strong ground motions and a background (off asperity) that has no stress drop, moves with the asperities, and generates weak ground motions only. The asperity model is described by six major parameters: the seismic fault area, averaged stress drop on the seismic fault, asperity area, asperity stress drop, seismic moment, and shortperiod level. Here, the seismic fault area is the part of the fault area (ruptured area) in the seismogenic layer, and the short-period level is the flat level of the acceleration source spectrum (Dan et al., 2001), that is similar to the high-frequency level by Atkinson and Beresnev (1997). The six major parameters are evaluated from the active fault length and the thickness of the seismogenic layer by empirical or theoretical relationships among the parameters, which has been compiled by Irikura's research papers (e.g., Irikura and Miyake, 2001) as a recipe for predicting strong ground motions. His recipe has been adopted by Headquarters of Earthquake Research Promotion, Japan (2005a).

On the other hand, for long faults in the crust such as the Median Tectonic Line, Japan, this recipe produces negative slip on the background, whose direction is opposite to the slip direction on the asperity, 
because the asperity area becomes over $50 \%$ of the seismic fault area (Headquarters of Earthquake Research Promotion, 2005b) and the slip on the asperities is assumed to be twice the averaged slip on the entire seismic fault.

On the other hand, Irie et al. (2010a) carried out dynamic fault rupturing simulations of long vertical strike-slip faults with a free-stress surface, and obtained an approximation equation of the proportionality constant for calculating the averaged dynamic stress drop from the seismic fault area and the seismic moment. Moreover, Irie et al. (2013) obtained an approximation equation of the proportionality constant for long reverse faults.

Dan et al. (2011) estimated the averaged dynamic stress drop and the dynamic stress drop on the asperity of the vertical strike-slip faults by using the approximation equation by Irie et al. (2010a). Based on these values, they proposed a procedure for evaluating parameters of vertical strike-slip faults for strong motion prediction.

Dan et al. (2015) also applied the approximate equation of the averaged dynamic stress drop for reverse faults by Irie et al. (2013) to the earthquakes caused by reverse faults, and estimated the averaged dynamic stress drops on the seismic faults and the dynamic stress drops on the asperities. Based on these values, they proposed a procedure for evaluating parameters of reverse faults for strong motion prediction.

In order to validate the new procedure by Dan et al. (2011), we evaluated fault parameters of the asperity model whose length was $141 \mathrm{~km}$ by this procedure, predicted strong motions by the stochastic Green's function method by Boore (1983), and compared the predicted results with the actual strong motion records during the 1999 Kocaeli, Turkey, earthquake $\left(M_{W} 7.6\right)$ whose fault is $141 \mathrm{~km}$ long and with the ground motion prediction equation (GMPE) proposed by Kale et al. (2015) for Turkey earthquakes. We also evaluated fault parameters of the asperity model whose length was $279 \mathrm{~km}$, in order to validate the new procedure by Dan et al. (2015), predicted strong motions, and compared the predicted results with the actual strong motion records during the 2008 Wenchuan, China, earthquake $\left(M_{W} 7.9\right)$ whose fault is $279 \mathrm{~km}$ long and with the GMPE proposed by Campbell and Bozorgnia (2014) for reversefault earthquakes.

\section{VALIDATION OF THE NEW PROCEDURE FOR EVALUATING PARAMETERS OF LONG STRIKE-SLIP FAULTS}

\section{Procedure for Evaluating Parameters of Long Vertical Strike-Slip Faults}

Dan et al. (2011) proposed a procedure shown in Figure 1 for evaluating the fault parameters of long strike-slip faults. In the figure, ss indicates the averaged dynamic stress drop on the seismic fault, the dynamic stress drop on the asperities, and the constant $c$ for strike-slip faults.

\section{Asperity Model for the 1999 Kocaeli, Turkey, Earthquake}

In order to validate the procedure of evaluating parameters of vertical strike-slip faults, we took the 1999 Kocaeli, Turkey, earthquake $\left(M_{W} 7.6\right)$, whose fault length is $141 \mathrm{~km}$ and fault width is $23.3 \mathrm{~km}$, as an example. Hence, we evaluated fault parameters for a $141-\mathrm{km}$ long and $23.3-\mathrm{km}$ wide vertical strikeslip fault by the procedure in Figure 1. Here, we assumed the upper depth of the seismogenic layer to be 3 $\mathrm{km}$. The moment magnitude was evaluated to be 7.7 from the seismic fault length of $141 \mathrm{~km}$ and width of $20.3 \mathrm{~km}$ and $M_{W}=\left(\log M_{0}[\mathrm{~N}-\mathrm{m}]-9.1\right) / 1.5$.

Figure 2(a) shows the locations of the surface projection of the fault model and the observation stations. Figure 2(b) shows the asperity model evaluated by the procedure. The number and the locations of the asperities were assumed based on the fault model of this earthquake obtained by Kamae and Irikura (2002). The hypocenter was also assumed based on that of this earthquake.We distributed the calculation points at $5-\mathrm{km}$ grids within $70 \mathrm{~km}$ from the fault trace, totaling 1682 points.

\section{Stochastic Green's Function Method}


We adopted the stochastic Green's function method by Boore (1983). The Fourier amplitude of the stochastic Green's function is described by

$$
\begin{gathered}
A m p_{s g f}(f)=\frac{F^{S}}{4 \pi \rho_{\text {seis }} \beta_{\text {seis }}^{3}} \times \frac{M_{0 s g f}}{1+\left(f / f_{\text {csg }}\right)^{2}} \times \frac{1}{\sqrt{1+\left(f / f_{\text {max }}\right)^{m}}} \times \exp \left[-\frac{\pi f r}{Q(f) \beta_{\text {seis }}}\right] \times 2 \sqrt{\frac{\rho_{\text {seis }} \beta_{\text {seis }}}{\rho_{s} \beta_{s}}} \\
f_{\text {csgf }}=\beta_{\text {seis }} \sqrt{\frac{\Delta \sigma}{\pi M_{0 s g f}}} \sqrt[4]{\frac{S_{\text {sgf }}}{\pi}}
\end{gathered}
$$

Here, the subscript $s g f$ stands for the stochastic Green's function, $f$ is the frequency, $F^{S}$ is the radiation pattern coefficient for $S H$ - or $S V$-waves, $\rho_{\text {seis }}$ and $\beta_{\text {seis }}$ are the density and $S$-wave velocity at the source, $r$ is the hypocentral distance, $f_{c}$ is the corner frequency, $f_{\max }$ is the cut-off frequency (Hanks, 1982), $m$ is a constant, $Q(f)$ is the quality factor along the wave propagation path, 2 is a constant that accounts for the free-surface effect, $\rho_{s}$ and $\beta_{s}$ are the density and $S$-wave velocity of the shallowest surface layer at the evaluation sites.

In the actual calculation, the radiation pattern coefficients $F^{S}$ were based on the values proposed by Satoh (2002a) for the aftershocks of the 2002 Tottori-ken Seibu, Japan, earthquake and by Satoh (2002b) for the 1998 Miyagi-ken Nanbu earthquake, i.e., we adopted the theoretical radiation pattern coefficients by Aki and Richards (1980) for frequencies lower than $3 \mathrm{~Hz}$ and the value of 0.445 for frequencies higher than $6 \mathrm{~Hz}$, which is the average of the theoretical radiation pattern values over all azimuths and various ranges of takeoff angles (Boore and Boatwright, 1984), and interpolated the values between the theoretical radiation pattern coefficient and 0.445 for frequencies $3 \mathrm{~Hz}$ to $6 \mathrm{~Hz}$. We selected the positive or negative sign of 0.445 to match the sign of the theoretical radiation pattern coefficient. The density and $S$-wave velocity at the source were $\rho_{\text {seis }}=2.7 \mathrm{~g} / \mathrm{cm}^{3}$ and $\beta_{\text {seis }}=3.5 \mathrm{~km} / \mathrm{s}$, respectively, which were the layerthickness-weighted averages over the soil layers at the seismic fault (Sekiguchi and Iwata, 2002). The hypocentral distance $r$ was calculated from the evaluation points to the center of the fault. The seismic moment $M_{0}=3.26 \times 10^{16} \mathrm{~N}-\mathrm{m}$ was calculated by equation of a crack model (Eshelby, 1957) for the subfault size $2.82 \mathrm{~km} \times 2.9 \mathrm{~km}$ and average stress drop $\Delta \sigma=3.4 \mathrm{MPa}$. Then, the corner frequency $f_{\text {csg }}=0.8 \mathrm{~Hz}$ was calculated by equation (2). As for the $f_{\max }$ term in equation (1), $f_{\max }$ was fixed at $6 \mathrm{~Hz}$ as in Tsurugi et al. (1997) for the 1995 Kobe, Japan, earthquake, and $m$ was set to be 4.2 as advised by Headquarters of Earthquake Research Promotion (2005a). The quality factor was $Q(f)=300 f$ for $f \geqq 0.8 \mathrm{~Hz}$ and $Q=240$ for $f$

$<0.8 \mathrm{~Hz}$, taking into account its frequency dependence and the velocity models at the evaluation sites (Sekiguchi and Iwata, 2002). The density and the $S$-wave velocity of the shallowest surface layer were $\rho_{s}=2.43 \mathrm{~g} / \mathrm{cm}^{3}$ and $\beta_{s}=2.71 \mathrm{~km} / \mathrm{s}$, respectively (Sekiguchi and Iwata, 2002).

We adopted the envelope time function $\operatorname{Env}(t)$ of the following equations proposed by Boore (1983).

\section{Comparison of the Predicted Strong Ground Motions with the Records and GMPE}

Figure 3 compares the velocity waveforms and pseudo velocity response spectra of the predicted motions with those of the records observed at GBZ during the 1999 Kocaeli, Turkey, earthquake (USGS, 2001) and with the median and the standard deviation of the ground motion prediction equation (GMPE) proposed by Kale et al. (2015) for Turkey earthquakes. The prediceted velocity waveform in the NS direction agrees well with the observed one, while the predicted velocity waveform in the EW direction is underestimated. This might be because the radiation pattern of the SH waves from the vertical strike-slip fault is included too purely in the EW component waveform, i.e. the seismic waves are scattered and do not obey the theoretical radiation pattern. The predicted pseudo velocity response spectra within $20 \mathrm{~km}$ from the fault trace have the deviation covering the response spectra observed at GBZ, $14.2 \mathrm{~km}$ away from the fault trace. The GMPE proposed by Kale et al. (2015) shows a good agreement with the observed response spectra as well as the predicted response spectra in the period range shorter than 0.3 seconds, but it is rather smaller than the observed and predicted ones in the period range longer than 0.4 seconds. 
Figure 4 shows the comparison of the peak ground accelerations and velocities of the predicted ground motions with those of the records observed during the 1999 Kocaeli, Turkey, earthquake. The open circles are the predicted, and the solid circles are the observed. The predicted peak ground accelerations and velocities agree pretty well with those of the records.

\section{VALIDATION OF THE NEW PROCEDURE FOR EVALUATING PARAMETERS OF LONG REVERSE FAULTS}

\section{Procedure for Evaluating Parameters of Long Dipping Reverse Faults}

Dan et al. (2015) proposed a procedure shown in Figure 1 for evaluating the fault parameters of long reverse faults. In the figure, $\mathrm{rv}$ indicates the averaged dynamic stress drop on the seismic fault, the dynamic stress drop on the asperities, and the constant $c$ for reverse faults.

\section{Asperity Model for the 2008 Wenchuan, China, Earthquake}

In order to validate the procedure of evaluating parameters of reverse faults, we took the 2008 Wenchuan, China, earthquake $\left(M_{W} 7.9\right)$, whose fault length is $279 \mathrm{~km}$ and fault width is $46 \mathrm{~km}$, as an example. Hence, we evaluated fault parameters for a $279-\mathrm{km}$ long and $46-\mathrm{km}$ wide reverse fault by the procedure in Figure 1. Here, we assumed the upper depth of the seismogenic layer to be $3 \mathrm{~km}$. The moment magnitude was evaluated to be 8.2 from the seismic fault length of $279 \mathrm{~km}$ and width of $40.6 \mathrm{~km}$ and $M_{W}=\left(\log M_{0}[\mathrm{~N}-\mathrm{m}]-9.1\right) / 1.5$.

Figure 5(a) shows the locations of the surface projection of the fault model and the observation stations. Figure $5(\mathrm{~b})$ shows the asperity model evaluated by the procedure. The number and the locations of the asperities were assumed based on the fault model of this earthquake obtained by Kurahashi (2011). The hypocenter was also assumed based on that of this earthquake. We distributed the calculation points at 5$\mathrm{km}$ grids within $50 \mathrm{~km}$ in the foot-wall zone and $100 \mathrm{~km}$ in the hanging-wall zone from the fault trace, totaling 2387 points.

\section{Stochastic Green's Function Method}

We applied the same procedure of the stochastic Green's function method as that for the 1999 Kocaeli, Turkey, earthquake to the simulation of the strong ground motions during the 2008 Wenchuan, China, earthquake. The $S$-wave velocity at the source was $\beta_{\text {seis }}=3.6 \mathrm{~km} / \mathrm{s}$, which was the layer-thickness-weighted average over the soil layers at the seismic fault (Kurahashi and Irikura, 2010). The density was $\rho_{\text {seis }}=2.8$ $\mathrm{g} / \mathrm{cm}^{3}$, which was obtained empirically from the $S$-wave velocity (Ludwig et al., 1970). The seismic moment $M_{0}=1.08 \times 10^{17} \mathrm{~N}-\mathrm{m}$ was calculated by equation of a crack model (Eshelby, 1957) for the subfault size $5.58 \mathrm{~km} \times 4.1 \mathrm{~km}$ and average stress drop $\Delta \sigma=2.4 \mathrm{MPa}$. Then, the corner frequency $f_{\text {csg }}=0.5 \mathrm{~Hz}$ was calculated by equation (2). The quality factor was $Q(f)=40 f$ for $f \geqq 0.8 \mathrm{~Hz}$ and $Q(f)=32$ for $f<0.8 \mathrm{~Hz}$ based on Satoh and Okazaki (2008). Since the soil at the observation stations is not hard rock, we assumed the density and $S$-wave velocity of the shallowest surface layer to be $\rho_{s}=1.96 \mathrm{~g} / \mathrm{cm}^{3}$ and $\beta_{s}=0.6$ $\mathrm{km} / \mathrm{s}$, respectively.

\section{Comparison of the Predicted Strong Ground Motions with the Records and GMPE}

Figure 6(a) compares the velocity waveforms of the predicted motions with those of the records observed at MZQ during the 2008 Wenchuan, China, earthquake (Wen et al., 2010). The prediceted velocity waveforms agree well with the observed ones at MZQ, $3.2 \mathrm{~km}$ away from the fault trace. Figure 6(b) compares the pseudo velocity response spectra of the predicted ground motions within $10 \mathrm{~km}$ from 
the fault trace with the median and the standard deviation of the GMPE proposed by Campbell and Bozorgnia (2014) for reverse-fault earthquakes. The predicted response spectra correspond to the median minus one standard deviation of the GMPE in the period range shorter than 0.1 second and the median minus a half standard deviation in the period range longer than 0.2 seconds.

Figure 7 shows the comparison of the peak ground accelerations and velocities of the predicted ground motions with those of the records observed during the 2008 Wenchuan, China, earthquake (Si et al., 2010). The open circles are the predicted, and the solid circles are the observed. The predicted peak ground accelerations and velocities agree pretty well with those of the records.

\section{CONCLUSIONS}

In order to validate the new procedure by Dan et al. (2011) for long strike-slip faults, we made an asperity model for a strike-slip fault $141 \mathrm{~km}$ long by this procedure for strike-slip faults, predicted ground motions by the stochastic Green's function method, and showed that the predicted velocity motions, velocity response spectra, PGA's, and PGV's agreed well with the observed ones in the 1999 Kocaeli, Turkey, earthquake $\left(M_{W} 7.6\right)$. We also made an asperity model for a reverse fault $279 \mathrm{~km}$ long by the new procedure by Dan et al. (2015) for long reverse faults, and showed that the predicted velocity motions, PGA's, and PGV's agreed well with the observed ones in the 2008 Wenchuan, China, earthquake $\left(M_{W}\right.$ 7.9). We can conclude that the two new procedures can be applied to the evaluation of the fault parameters of fault width-limited earthquakes for the ground motion prediction.

\section{ACKNOWLEDGEMENTS}

Simulating the strong ground motions for the 1999 Kocaeli, Turkey, earthquake and the 2008 Wenchuan, China, earthquake in this paper is the results of the project by National Research Institute for Earth Science and Disaster Resilience. We appreciate Dr. Hongjun Si at the University of Tokyo for providing us with the peak accelerations and peak velocities in the 2008 Wenchuan, China, earthquake and Dr. Yasuo Okada at Shimizu Corporation for allowing us to use his program generating stochastic Green's functions.

\section{REFERENCES}

Aki, K. and Richards, P. G. (1980). Quantitative Seismology, W. H. Freeman and Company, New York. Atkinson, G. M. and Beresnev, I. (1997). "Don’t call it stress drop," Seismol Res Lett 68, 3-4.

Boore, D. M. (1983). "Stochastic simulation of high-frequency ground motions based on seismological models of the radiated spectra," Bull Seismol Soc Am 73, 1865-1894.

Boore, D. M. and Boateright, J. (1984). "Average body-wave radiation coefficients," Bull Seismol Soc Am $74,1615-1621$.

Campbell, K. W. and Bozorgnia, Y. (2014). "NGA-West2 ground motion model for the average horizontal components of PGA, PGV, and 5\% damped linear acceleration response spectra," Earthquake Spectra 30, 1087-1115.

Dan, K., Watanabe, T., and Tanaka, T. (1989). "A semi-empirical method to synthesize earthquake ground motions based on approximate far-field shear-wave displacement," J Struct Constr Eng AIJ 396, 27-36 (in Japanese with English abstract).

Dan, K., Watanabe, M., Sato, T., and Ishii, T. (2001). "Short-period source spectra inferred from variableslip rupture models and modeling of earthquake fault for strong motion prediction," J Struct Constr Eng AIJ 545, 51-62 (in Japanese with English abstract).

Dan, K., Ju, D., Irie, K., Arzpeima, S., and Ishii, Y. (2011). "Estimation of averaged dynamic stress drops of inland earthquakes caused by long strike-slip faults and its application to asperity models for predicting strong ground motions," J Struct Constr Eng AIJ 670, 2041-2050 (in Japanese with English abstract). 
Dan, K., Irie, K., Ju, D., Shimazu, N., and Torita, H. (2015). "Procedure for estimating parameters of fault models of inland earthquakes caused by long reverse faults," J Struct Constr Eng AIJ 707, 47-57 (in Japanese with English abstract).

Hanks, T. C. (1982). " $\mathrm{f}_{\max }$," Bull Seismol Soc Am 72, 1867-1879.

Headquarters of Earthquake Research Promotion (2005a). "Map of Predicted Earthquake Ground Motions in Japan," (in Japanese).

Headquarters of Earthquake Research Promotion (2005b). "Strong Ground Motions Predicted in the Earthquakes Caused by the Yamazaki Fault, Japan," (in Japanese).

Irie, K., Dan, K., Ikutama, S., and Irikura, K. (2010). "Improvement of kinematic fault models for predicting strong motions by dynamic rupturing simulation -Evaluation of proportionality constant between stress drop and seismic moment in strike-slip inland earthquakes-," First Kashiwazaki International Symposium on Seismic Safety of Nuclear Installations.

Irie, K., Dan, K., Torita, H., and Kase, Y. (2013). "Estimation of dynamic stress drops of inland earthquakes caused by long reverse faults," Proc. of the 10th Annual Meeting of Japan Association for Earthquake Engineering, 375-376 (in Japanese).

Irikura, K. and Miyake, H. (2001). "Prediction of strong ground motions for scenario earthquakes," Journal of Geography 110, 849-875 (in Japanese with English abstract).

Kale, Ö., Akkar, S., Ansari, A., and Hamzehloo, H. (2015). "A ground-motion predictive model for Iran and Turkey for horizontal PGA, PGV, and 5\% damped response spectrum: Investigation of possible regional effects," Bull Seismol Soc Am 105, 963-980.

Kamae, K. and Irikura, K. (2002). "Source characterization and strong motion simulation for the 1999 Kocaeli, Turkey and the 1999 Chi-Chi, Taiwan earthquakes," Proceedings of the 11th Japan Earthquake Engineering Symposium, 545-550.

Kurahashi, S. and Irikura, K. (2010). "Characterized source model for simulating strong ground motions during the 2008 Wenchuan earthquake," Bull Seismol Soc Am 100, 2450-2475.

Kurahashi, S. (2011). http://hdl.handle.net/11133/2563 (Referred on November 1, 2016)

Ludwig, W. J., Nafe, J. E., and Drake, C. L. (1970). "Seismic Refraction," The Sea 4, Part 1, 53-84.

Matsushima, S. and Kawase, H. (2006). "Re-evaluation of near source ground motion and damage belt of the Hyogo-ken Nanbu earthquake of 1995," Summaries of Technical Papers of Annual Meeting, AIJ, 271-272 (in Japanese).

Satoh, T. (2002a). "Radiation Pattern and fmax of the Tottori-Ken Seibu earthquake and the aftershocks inferred from KiK-net strong motion records," J Struct Constr Eng AIJ 556, 25-34 (in Japanese with English abstract).

Satoh, T. (2002b). "Empirical frequency-dependent radiation pattern of the 1998 Miyagiken-Nanbu earthquake in Japan," Bull Seismol Soc Am 92, 1032-1039.

Satoh, T. and Okazaki, A. (2008). "Scaling of short-period level and total area of asperities of the 2007 Niigata Chuetsu-oki earthquake and the 2004 Niigata Chuetsu earthquake," The 7th General Assembly of Asian Seismological Commission and the 2008 Fall Meeting of Seismological Society of Japan Y1-202, 305.

Sekiguchi, H. and Iwata, T. (2002). "Rupture process of the 1999 Kocaeli, Turkey, earthquake estimated from strong-motion waveforms," Bull Seismol Soc Am 92, 300-311.

Si, H., Hao, K. X., Xu, Y., Senna, S., Fujiwara, H., Yamada, H., Tsutsumi, H., Wu, C., Midorikawa, S., and Irikura, K. (2010). "Attenuation characteristics of peak ground motions during the $\mathrm{M}_{\mathrm{W}} 7.9$ Wenchuan earthquake, China," 7th International Conference on Urban Earthquake Engineering \& 5th International Conference on Earthquake Engineering, 103-106.

Tsurugi, M., Kagawa, T., Irikura, K., and Kowada, A. (1997). "Cutoff frequency $f_{\max }$ of earthquakes occurring in Kinki district," Japan Earth and Planetary Science Joint Meeting, 103 (in Japanese).

USGS (2001). "Main shock and aftershock records of the 1999 Izmit \& Duzce, Turkey earthquakes," USGS/OFDA PROJECT [USGS PROJECT NO: 1-7460-63170].

Wen, Z., Xie, J., Gao, M., Hu, Y., and Chau, K. T. (2010). "Near-Source strong ground motion characteristics of the 2008 Wenchuan earthquake," Bull Seismol Soc Am 100, 2425-2439. 
$24^{\text {th }}$ Conference on Structural Mechanics in Reactor Technology

BEXCO, Busan, Korea - August 20-25, 2017

Division IX (include assigned division number from I to X)
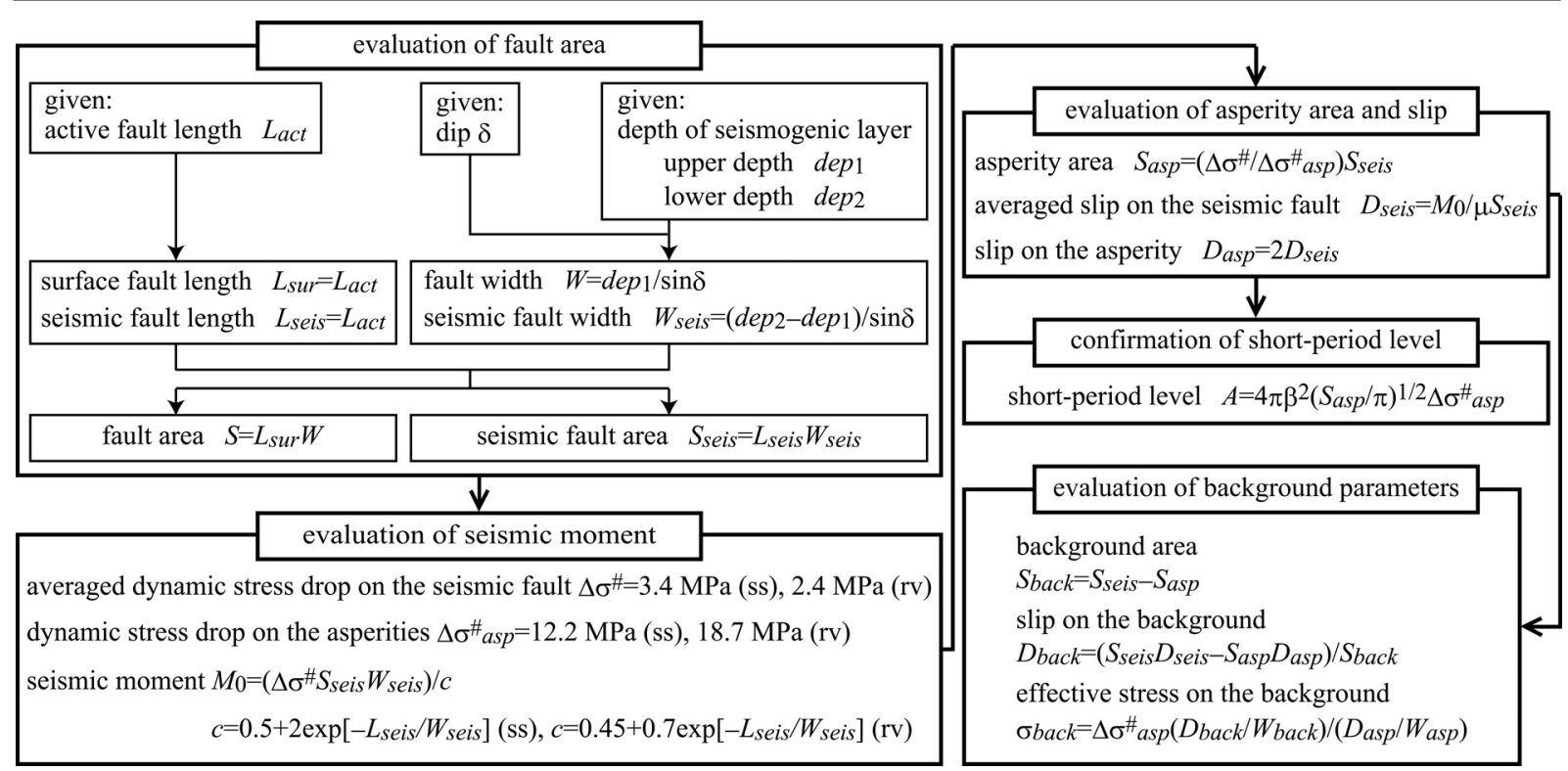

Figure 1. Procedure for evaluating parameters of strike-slip faults(ss) and reverse faults(rv) for strong motion prediction (Dan et al., 2011; Dan et al., 2015).

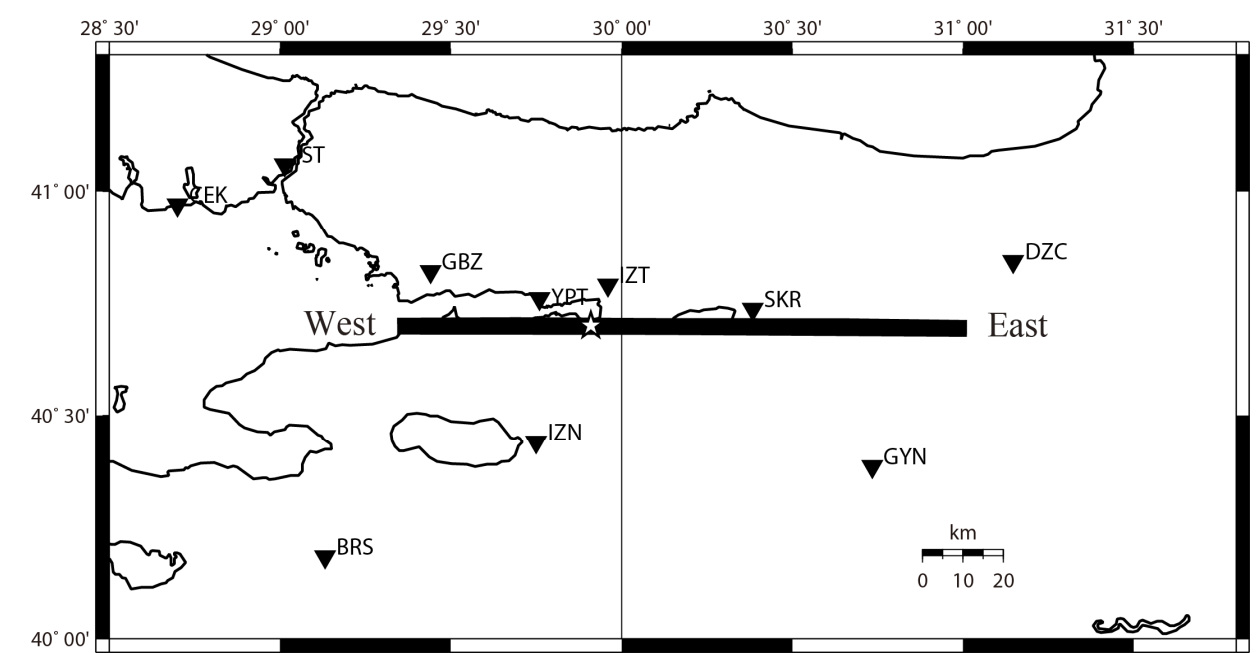

(a) Locations of the surface projection of the fault model and the observation stations

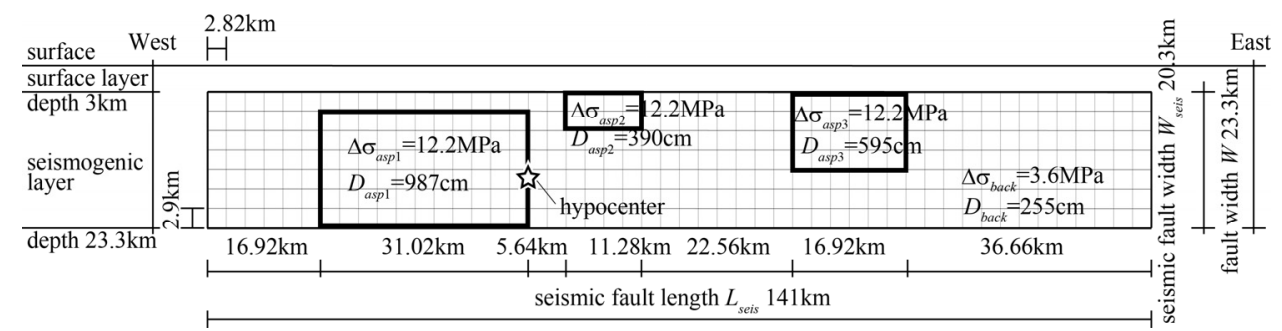

(b) Asperity model

Figure 2. Asperity model evaluated by the proposed procedure in Figure 1 for a 141-km long vertical strike-slip fault. 

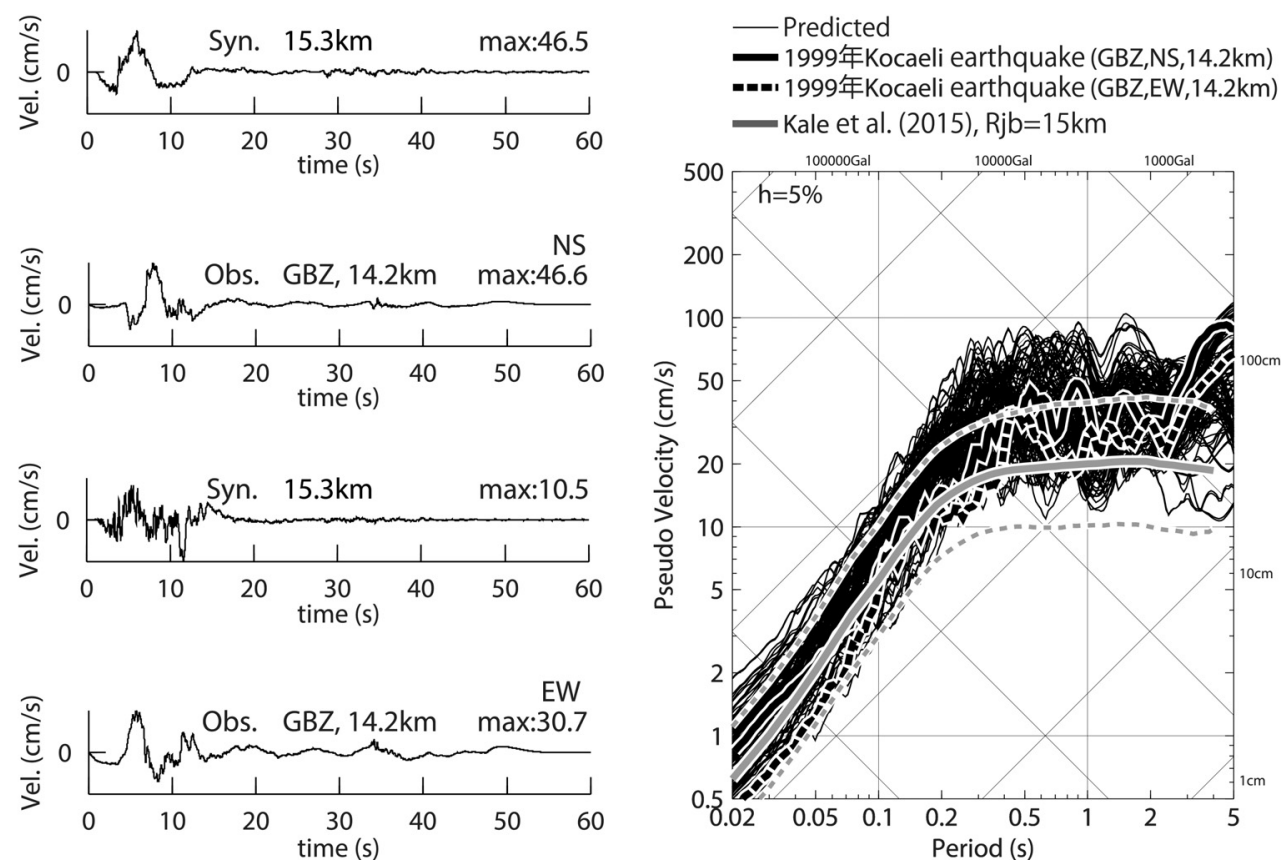

(a) velocity waveforms

(b) pseudo velocity response spectra

Figure 3. Comparison of the velocity waveforms and pseudo velocity response spectra of the predicted motions with those of the records observed at GBZ during the 1999 Kocaeli, Turkey, earthquake and with the median and the standard deviation of the GMPE proposed by Kale et al. (2015) for Turkey earthquakes.

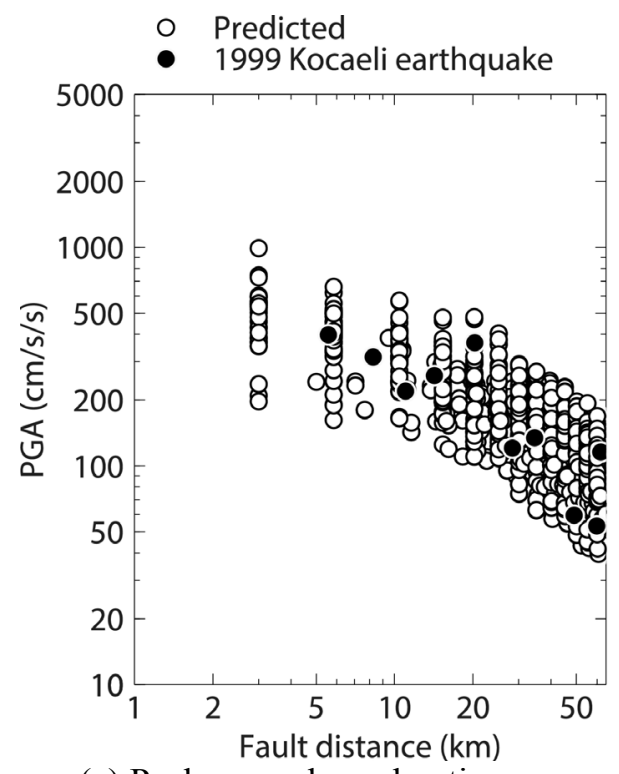

(a) Peak ground accelerations

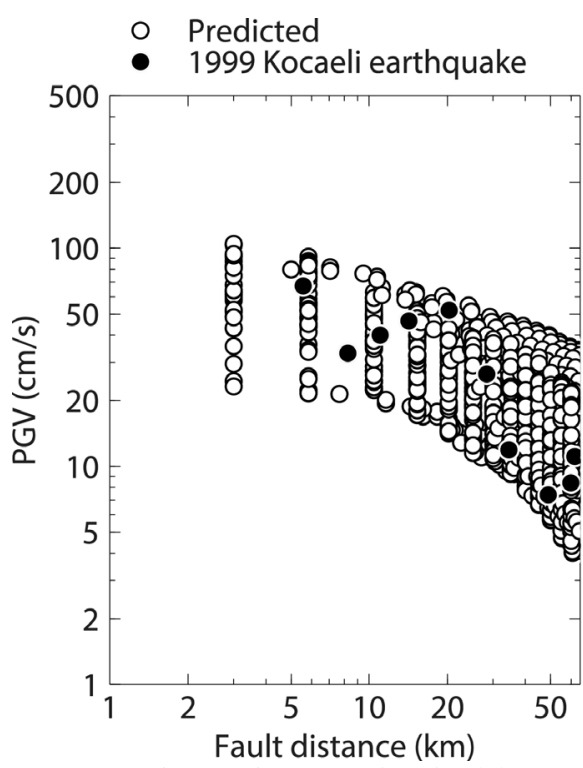

(b) Peak ground velocities

Figure 4. Comparison of the peak ground accelerations and velocities of the predicted ground motions with those of the records observed during the 1999 Kocaeli, Turkey, earthquake. 
$24^{\text {th }}$ Conference on Structural Mechanics in Reactor Technology

BEXCO, Busan, Korea - August 20-25, 2017

Division IX (include assigned division number from I to X)

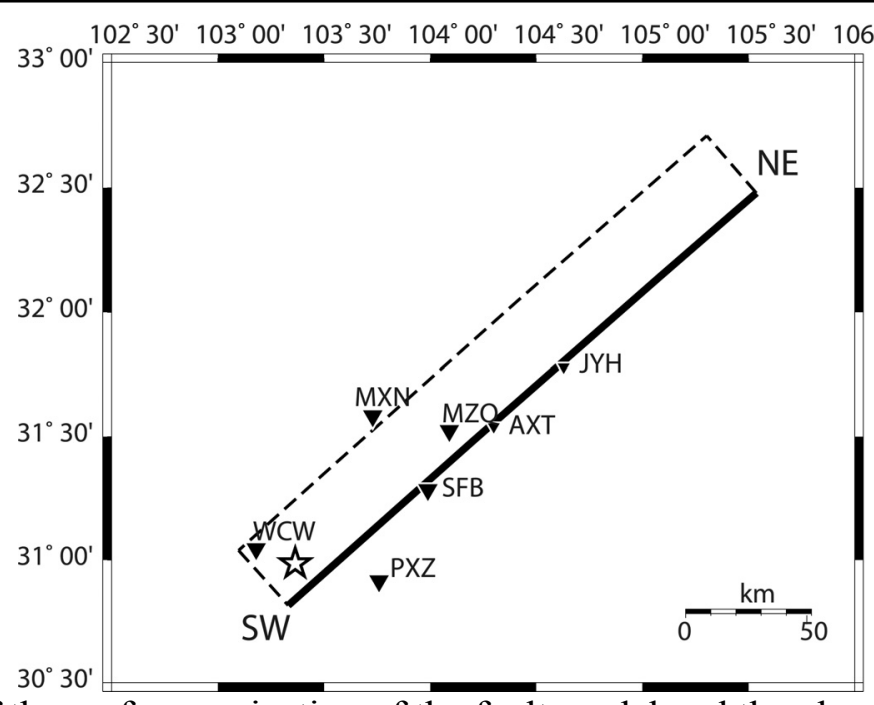

(a) Locations of the surface projection of the fault model and the observation stations
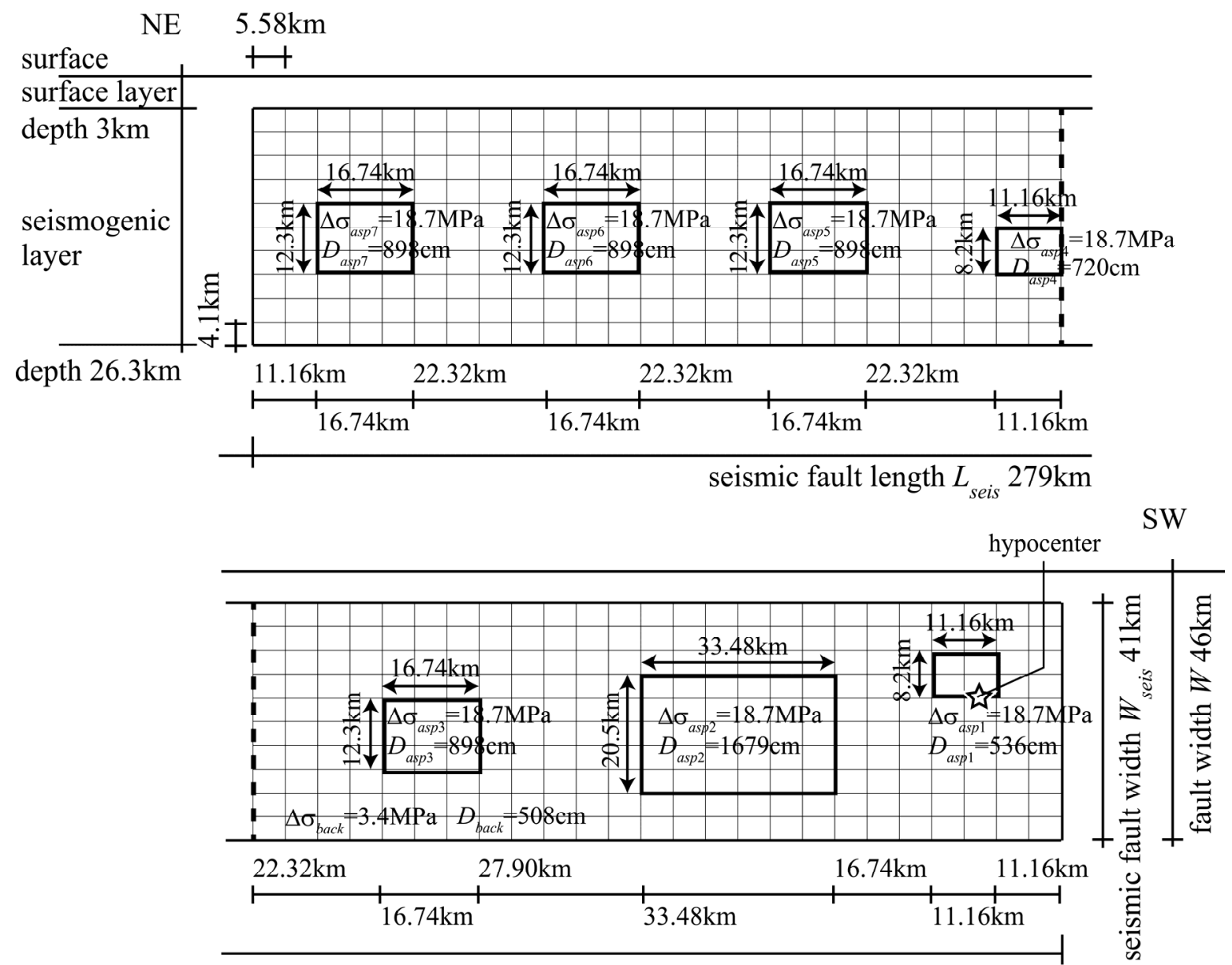

(b) Asperity model

Figure 5. Asperity model evaluated by the proposed procedure in Figure 1 for a 279-km long reverse fault. 

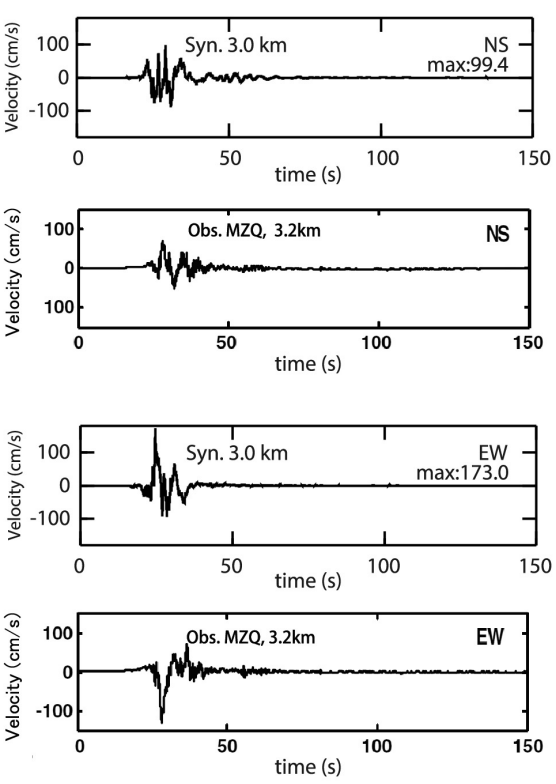

(a) Velocity waveforms

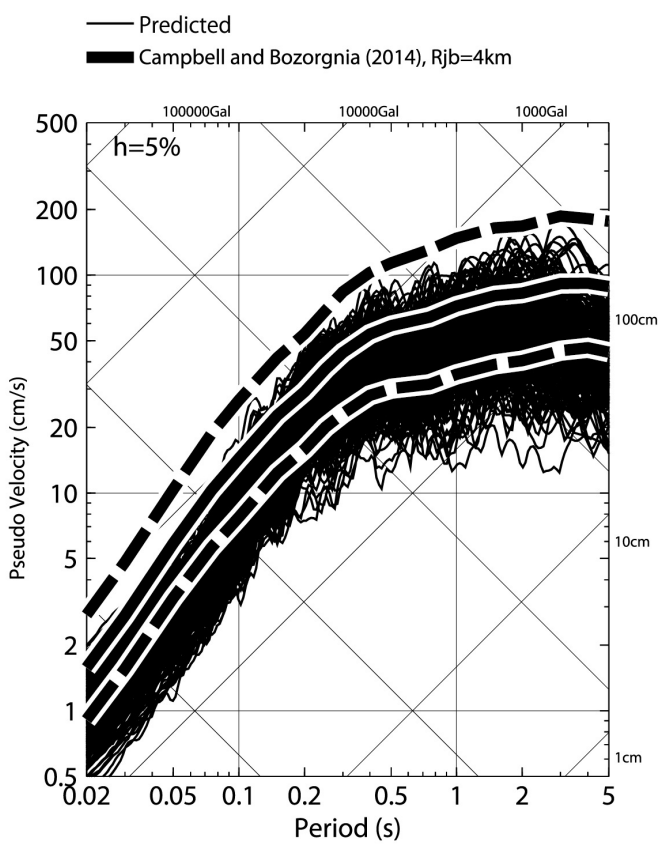

(b) Pseudo velocity response spectra

Figure 6. Comparison of the velocity waveforms and pseudo velocity response spectra of the predicted motions with those of the records observed at MZQ during the 2008 Wenchuan, China, earthquake and with the median and the standard deviation of the GMPE proposed by Campbell and Bozorgnia (2014) for reverse-fault earthquakes.

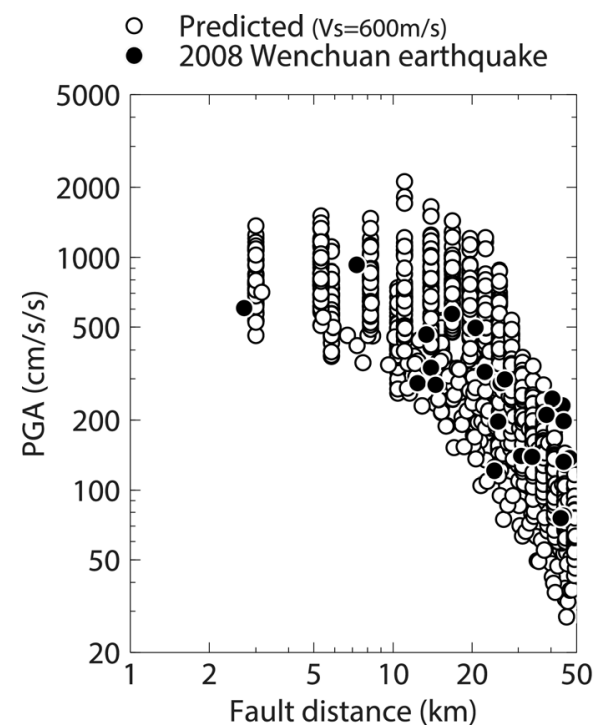

(a) Peak ground accelerations

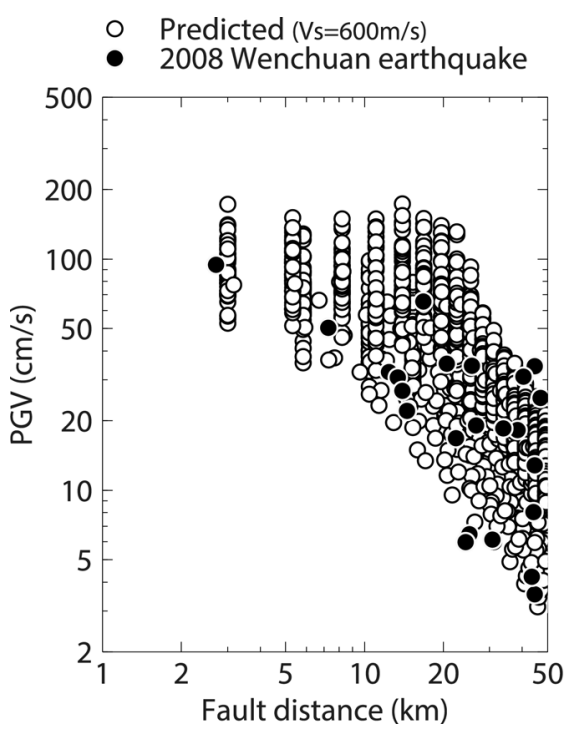

(b) Peak ground velocities

Figure 7. Comparison of the peak ground accelerations and velocities of the predicted ground motions with those of the records observed during the 2008 Wenchuan, China, earthquake. 